\title{
The Flowers Report: opportunities missed
}

Dr R. H. Mole, Director of the MRC Radiobiology Unit at Harwell, offers some personal reflections on the recent nuclear power report of the Royal Commission on Environmental Pollution

THE Report's main conclusion is that there are substantial environmental objections to a nuclear power programme on the scale envisaged (paragraph 534) and that we should not rely for energy supply on a process that produces such a hazardous substance as plutonium unless there is no reasonable alternative (paragraph 535). In an earlier paragraph (186), the conclusion is much more categorical: although aware of the advantages that nuclear power offers the Commission did not think that these outweigh the risks described. Routine electricity production by nuclear means, however, appears to be regarded as unobjectionable.

It is necessary to consider important omissions from the Report, so important as to appear to warrant asking whether these conclusions are justified.

\section{The human cost}

The routine environmental effects of nuclear power may well be much less damaging than those of fossil fuelled power stations ... The discharges of radioactivity from nuclear stations, both to air and water, are radiographically insignificant and there are no discharges of offensive gases or particulates. (191).

the aspects of nuclear development which cause most dissension tend to be those that relate not to normal operation but to the possibility of abnormal events such as accidents at nuclear installations or malevolent acts against them. (10).

Although the Report says that the Commission "should be concerned not so much with the individual risk as with the total effect of possible accidents" (173) this total effect is never considered. The human cost of nuclear power is considered and enumerated only in relation to single examples of what were said to be very unlikely events, an exceptional release of radioactivity into the sea at Windscale (139) or into the atmosphere from a serious reactor accident (263-268). There is nothing in the Report to show that the Commission considered or enumerated the total casualty rate from reactor malfunctions and small accidents which will occur much more frequently than exceptional severe accidents, or even from the routine operation of power reactors without malfunction. Is it a mistake to conclude that, when the Commission concentrated on exceptional occurrences, it did not know whether it had addressed itself to the real problem of nuclear safety or only to a minor aspect of it?

In relation to the possibility of terrorist activities the Commission con- tented itself with stressing that purloining enough plutonium to make a crude bomb is bound to happen sooner or later but did not attempt to deduce the likely or possible consequences in terms of numbers of casualties. Thus on this question the Royal Commission with all its expertise and resources has added nothing to what has been said repeatedly over the past few years by the ordinary journalist.

\section{Energy Strategy}

Chapter IX on Energy Strategy considers energy needs and alternative means of satisfying those needs but nowhere considers the human costs of getting energy by any means, except to take for granted that nuclear power is basically hazardous. Much of the Report's anxiety seems to be based on "the assumed necessity of securing steadily increasing energy supplies" (197) as illustrated in Table 14. But no facts are provided to enable the reader to consider what methods of supplying energy might be the safest to the population and the least damaging to the environment if there was no need to increase energy supplies at all. Chapter VI is said to relate nuclear and nonnuclear hazards (16) but it does not do this for alternative means of getting energy.

The Commission's failure to compare the human costs of alternative sources of energy and to consider the total effect of possible accidents can make its anxieties about exceptional serious accidents seem wholly unbalanced. This can be illustrated as follows. The current death rate from accidents amongst employees of the National Coal Board is in round terms $50-60$ per from a particular example of failure of containment of Caesium-137 at Windscale is given as perhaps fifty in total (spread out over many years). Such an event is said not to be at all likely and its consequences are used to illustrate the need for the strictest containment of radioactive wastes for very long periods (139), as if the number of casualties was something out of the ordinary and perhaps unacceptable to the Commission.

The large radioactivity release considered as an exceptional but very $10^{5} \mathrm{Ci}$ Caesium-137 and so on, and would give 110-350 deaths from cancer (263-268). This is the same as the number of accidental deaths in coal production in UK over a 2-6 year period year. The number of cancer deaths serious event is of $10^{7} \mathrm{Ci}$ Iodine-131, at the current annual rate. The probability of release of $10^{7} \mathrm{Ci}$ lodine-131 is $10^{-7}$ per reactor year (the Report's Figure 15). One hundred reactors each of $1,000 \mathrm{MW}$ would produce twice as much electricity as the whole of that generated by all means in UK in 1975 $(462,468)$, and the probability of release of $10^{7} \mathrm{Ci}$ Iodine-131 would then be once every 100,000 years. On this count alone nuclear power would appear to be more than 10,000 times safer than coal power.

Such a comparison is obviously inadequate since it is between a most exceptional event and a routine annual occurrence. It shows very clearly how misleading it may be to concentrate on exceptional events with large consequences and to ignore much commoner events each with relatively small consequences. Differences in emphasis on these contrasting sources of risk were in fact noted by the Royal Commission as the reason for inconsistencies in evidence on the policy for siting reactors (296), but the Commission seems to have failed to appreciate the significance of the matter for itself.

\section{Consistency in assessing}

the acceptability of risk

The Royal Commission emphasised the need for a body with statutory responsibility for endorsing the basic standards for radiological protection on the national behalf (223). Such a body must be clearly independent of any interests promoting developments involving radioactivity, it is agreed, but the conclusion can be questioned that "in view of the importance of the issues it should be a body constituted specifically for radiological protection" (223). Whatever the history of how the basic standards were chosen, they are expressed in terms of tissue dose and, therefore, can be specifically related to risk.

Technically this relation must be as exact as current scientific understanding will allow, but "the importance of the issues" at the present time is not so much the degree of technical accuracy as the acceptability of the corresponding risk. This cannot be wholly determined by any body specifically constituted only for radiological protection, as that phrase would normally be understood, because acceptability is not a radiological matter. The non-technical essence of the choice of basic standard is to set the corresponding level of risk at that point on the scale of risk which makes it acceptable in the light of all other sources of everyday risk in work and generally.

The Royal Commission recognised that the collective action of involved government departments was inad- 
equate for providing advice on energy strategy (515) and recommended the need for an independent high-level advisory body on the subject (535). All the more reason for recognising the need for a central body to consider and report publicly on the level of acceptability of risk in relation to the various means by which the great variety of national needs could be satisfied, energy supply being but one of these. Consistency in assessing acceptability of risk is required not only within the energy field but also between the energy field and other major national activities not excluding the practice of medicine.

For example, at the present time roughly as much lodine-131 is administered to patients, and from them is released into the environment each year, as would be released on average per year over the 100,000-year period within which one most exceptional release of $10^{7}-\mathrm{Ci}$ Iodine-131 might be expected from a hundred nuclear reactors routinely generating electricity.

\section{Public reaction to risks}

A major factor in the Royal Commission's approach, although not made wholly explicit, is expressed clearly enough in the Report: risks of events that affect people individually or in small numbers, it says, "are fairly readily accepted as inevitable", but events "that cause death or injury to many people at one time ... have, in proportion to the numbers affected, a much greater impact in creating public concern" (172 and see 270).

The Commission, in emphasising so strongly the exceptional event and accepting almost without question the safety of routine discharges of radioactivity into the environment, seems to have adopted the same attitude. Even if the members of the Royal Commission regarded themselves as in some sense representatives of the public or trustees of the national interest, there seems no reason why they should accept these public attitudes as given and unchangeable and approppriate for themselves. It was surely within their remit to attempt to change public attitudes by explanation and reason. This would certainly have to be a function of a central body to consider acceptability of risk, as suggested above, if it was to succeed in providing consistent guidelines on emotive subjects.

\section{Responsibilities and experts}

The Royal Commission found it difficult to obtain independent but expert advice "since the acknowledged experts are often themselves involved in the related developments" (163). So far as assessing the effect of pollutants, including radioactivity, "we can do no better than require that the agencies concerned are expert, open and in- dependent, and such as to ensure that necessary research is undertaken and that assessments are appropriately revised in the light of new knowledge. The requirement reflects on organisational arrangements" which are required (188).

The International Commission on Radiological Protection (ICRP) "is only as good as its members, and it is vitally important that these should continue to be appointed independently of the approval of their national governments and purely on the basis of their professional standing amongst their scientific peers... We hope that there will continue to be a strong British representation on the ICRP . . " (203).

A main problem, however, with the Commission's recommendations for systematising responsibilities is that they will still further reduce the possibilities of finding informed and at the same time independent experts. that is independent of interested organisations.

Bodies with statutory respnsibilities as proposed by the Commission, such as the strengthened NRPB, the Nuclear Waste Management Committee, the Nuclear Waste Disposal Corporation, the strengthened Health and Safety Executive (531) and HMPI (527), will clearly attract to themselves the best experts they can find. Any British members of ICRP will inevitably be found to belong to NRPB as, even now, three out of four current British members of ICRP do. Each such body will get financial support from government sources. Are they in the least likely to criticise each other publicly as the Royal Commission said they should be free to do? If an organisation has statutory responsibilities it must have a "party line" to which its employees conform. Even if, like NRPB at present, it is a national centre for advice without statutory responsibilities, it must ensure consistency in the advice it gives. Is this conducive to criticism from within of scientific or technological bases of action?

What the Royal Commission quite rightly seemed to desire was to maximise the possibilities for what might be called informed assent and dissent. This requires not only publicly available information but the existence of individuals who are not beholden to organisations with statutory responsibilities and who are technically educated and intellectually free to pursue argument and the advance of knowledge without the confinement of terms of reference or administrative boundaries.

Is there a big enough reservoir of such individuals for national needs? It wouldn't seem so for radiobiologists if major reports in Britain, like the Royal Commission's, and in the USA, like the
Rasmussen Report on Reactor Safety, were each radiobiologically defective, and the same reasoning can be applied to any other scientific field covered by the Royal Commission Report. The only way of remedying this sort of deficiency is to see that universities and polytechnics pay sufficient attention to the field of knowledge and that research councils play their part.

\section{Research priorities}

The Royal Commission regarded the arrangements for initiation and coordination of research as of the greatest importance but in no case was the priority of research discussed in relation to the quantitative importance of the subject matter as it relates to risk. Research could well be justified if a more than negligible risk is to be assessed but, if routine nuclear power is already known to be unobjectionable as suggested by the Commission, would research on its hazards be needed? It could hardly be justified merely by legislative requirements for annual surveys of discharges of radioactivity (251).

\section{Debate and accessibility of fact}

In its last few paragraphs the Royal Commission Report quite rightly stressed the importance of public understanding of the long term issues of unusual range and difficulty raised by nuclear development (521), and the need for open and deliberatc weighing of risks and costs of embarking on a major nuclear programme against those of not doing so (522). But such an open political process will generate only hot air and useless emotion unless there is an agreed basis of technological fact from which to start. The scientific convention is to provide a reference for every possibly arguable fact, and this systematic buttressing by checkable publications is something the dyed-inthe-wool scientific reader rather sadly misses. The enquirer cannot make the checks he may desire: for example, the source of only ten of 25 Figures and three of 14 Tables is acknowledged, and even then a specific reference is provided for only four of the 13 sources acknowledged. Perhaps a Royal Commission Report, especially if it deals with complex issues, is not a suitable place for a comprehensive reference list, but it must be a retreat from established scientific methodology if a Report of a Commission on highly technical questions is without adequate references because then its authority is simply the eminence of its individual members. This is a special problem in the present case, because many readers of different backgrounds have recognised serious defects in the Report.

For instance. the Royal Commission 
was concerned that insufficient research and attention had been given to atmospheric pollution by radioactivity (234), yet there is no evidence that the Commission knew of the more than 100 scientific papers on this subject published from the Environmental Sciences and Medical Division of AERE.

\section{Conclusions}

The Report of the Royal Commission on Environmental Pollution fails to provide (i) any evaluation of the relative level of risk of nuclear power from accidents and from normal operations, (ii) any corresponding evaluation of risk from other means of energy supply, (iii) any recommendation for a means of considering the level of risk in relation to acceptability on the national behalf.

Without (i) it would seem that the Royal Commission cannot know whether or not, in its emphasis on exceptional occurrences, it has tackled the real problem. Without (ii) its examination of Energy Strategy is woefully inadequate. Without (iii) its recommendation for a strongly based national body to consider radiological protection leaves that body with no standards by which to take decisions.
The Report concluded that plutonium must not be produced on a large scale until it is demonstrated that the plutonium can be taken care of safely. This is bound to be generally agreed. But safety is an open-ended concept and it must be a matter of judgment to decide whether what is known does or does not amount to the demonstration of a sufficient degree of safety. No criteria are provided by which such a judgment could be made.

Without all these, how can there be a deliberate weighing of the risks, costs and advantages of a major nuclear programme?

\section{Flowers on Flowers}

Sir Brian Flowers, who recently stepped down as Chairman of the Royal Commission after $3 \frac{1}{2}$ years, made his first public comments on reaction to the nuclear power report when he spoke at the British Nuclear Energy Society last week. Some extracts :

On the disposal of radioactive waste: "I have occasionally been asked what we meant by demonstrating a method beyond reasonable doubt. There appears to be agreement that a full programme of research might take a decade or more, but we argue that in any case we have that time available before becoming irretrievably committed to nuclear power as a major component of our electricity supply. I would suggest that what is needed in addition to a vigorous, systematic research programme is to choose and to set aside as soon as possible at least one specific site for which there is a consensus of geological, hydrological and other relevant opinion that it is acceptable for inaccessible disposal. It need not be the one eventually adopted, but it would provide a fall-back position. This, too, is a problem that exists irrespective of the future of nuclear power."

On alternative energy strategies: "The crucial long-term issues are on the one hand the competition between nuclear energy and coal, and on the other hand between both and renewable resources; and also between high electricity and therefore high heatwaste, on the one hand, and vigorous conservation measures on the other. Whether it is looked at from the industrial or the environmental point of view there is a very strong element of nuclear versus the rest. In these circumstances it is vital that responsible advice to Ministers should be seen to be independent of the major factions in the argument. I believe that it should be a matter of public concern that this is not at present the case."

On the possible effects of illicit activities: "On this issue, alone amongst all those we studied, we were given very little help by official bodies..

“. . . Probably the Government already has all the legal powers it would need under the Anti-Terrorist Acts of 1974 and 1976. Is Mr Eadie [Minister of State at the Department of Energy] saying that the Government has consciously resolved that the use of these powers is acceptable to safeguard the future electrical power industry? And that the changes then implicit for our society will be amply offset by the economic benefits of nuclear power? Perhaps he is, and perhaps he is right; but how are we to know unless we can discuss the matter? The Royal Commission does not know the answers to these questions. It merely considers them important and asks that they be discussed before we develop a reliance on nuclear power. If the Government continues to skulk behind the Official Secrets Act we may not know until it is too late to wish that it were otherwise."

\section{On nuclear weapons proliferation :} “... Thanks to the vested interests of the nuclear weapons states; thanks to the huge $R \& D$ resources already devoted to the development of nuclear power; thanks to the almost universal belief in a continuing abundance of cheap electricity, only recently shown to be a myth by the oil sheiks; thanks to the ensuing lack of attention paid to the need for energy conservation, the exploration of more meaningful long-term energy strategies, and the development of alternative sources; and on the global scale, thanks above all to the lack of any effective population control-it is simply not possible in 1976 to state with the required degree of certainty that the world need not be dependent on nuclear power beyond the end of this century. A severe lack of energy, and the continued division of the world into rich and poor which some would then envisage, might itself be extremely dangerous, even to the extent of bringing in the very nuclear hazards we were seeking to understand and if possible to lessen."

On the question of developing a commercial fast breeder reactor : "Judging by experience from other prototype reactors we shall still be learning a great deal from it in five or even ten years' time. In any case, it is now unrealistic to suppose that the first full-scale breeder reactor, the so-called CFR-1, could be started in under three or four years, even given the approval tomorrow. That gives ample time for the nuclear debate to come to a conclusion. I believe one should contemplate building any such reactor on a remote site contiguous with its own recycling plant so that there would be no need, after the first loading, for substantial quantities of plutonium to enter or leave the site. It is hardly likely that the result would justify the adjective 'commercial', but I believe it could be done in an environmentally acceptable fashion provided there is no commitment to an ongoing programme.

"But I see no need for undue speed, even if one believes there is no avoiding fast reactors and the plutonium economy they entail. Thermal reactor development has proved to be within the capacity of the United Kingdom, but only just. Fast reactor development is likely to be beyond our resources. It seems to me essential that if we pursue it at all we should do so on a Euronean basis. I can see no reason for wishing it were otherwise now that we are fully committed to the European Community . . ." 